\title{
A Stated Preference Analysis of Real-Time Public Transit Stop Information
}

\author{
Brian Caulfield and Margaret O'Mahony \\ Trinity College, Dublin, Ireland
}

\begin{abstract}
This paper presents the results of a study conducted to examine the benefits derived from real-time public transit stop information. This research examines the preferences between several options of receiving real-time public transit stop information. The literature states that one of the main reasons individuals access real-time information is to remove the uncertainty when using public transit. This relationship was examined to ascertain if the provision of real-time public transit information can remove the uncertainty and frustration associated with using public transit.

A nested logit model structure was applied in this study to examine the benefits derived from accessing real-time public transit information. These models are estimated on segments of the dataset to ascertain how the mode of transport used by the respondents impacts the benefits derived from using real-time public transit information. The results of this study demonstrate that passengers derive the greatest benefit from accessing transit stop information from real-time information displays. Respondents were shown to obtain the second highest utility when accessing transit stop information via a mobile phone short message service (SMS). Bus users were found to gain the highest benefit from the provision of real-time transit stop information.
\end{abstract}




\section{Introduction and Background}

Real-time public transit information is an individual-specific travel demand management tool that is used to facilitate individuals while planning their public transit trips. The provision of such information has been shown to encourage individuals to examine their public transit options and choose the service that meets their requirements.

The public transport system in Dublin consists of a large bus network, two light rail lines, and a heavy rail network. At the time of this study, there was no single source of public transit information on all modes of transit available in Dublin. This lack of information can act as a barrier to individuals making integrated public transit trips. Each of the public transit operators provides a website that contains timetables of all of the scheduled services and the routes provided. Dublin Bus in 2004 introduced a short message service (SMS) called "BUSTXT." This service provides users with the departure time from the terminus of the next three services in either direction when the user sends a message requesting information on a specific bus route. This service is available at a charge of 30c per message (Dublin Bus 2007). The information provided by this service is not real-time. In the same year, Irish Rail introduced a similar service for urban rail users called "DARTXT." The service works in a way similar to the Dublin Bus service; however, the information provided is real-time information. The cost of the service is $30 \mathrm{c}$ per message (Irish Rail 2007).

One of the main motivations for this research was to examine what information individuals require while waiting at their transit stop or station. Given that the cost of investment in providing real-time information is so large, it is important to understand what information individuals require. This research examines individuals' preferences for accessing real-time public transit information. To measure these preferences, a stated preference study was conducted to ascertain how respondents would value the introduction of several methods of public transit stop information.

Preferences for real-time public transit information are examined in this paper using a nested multi-nominal logit model. Several characteristics of an individual's trip, such as working hours and wait-time at stop/station, are examined to determine what impact they have on the benefits derived from real-time public transit information. 
Public transit users traditionally tend to overestimate their waiting time at stops/ stations (Nijkamp et al. 1996). Several studies have been conducted to ascertain if the provision of real-time information at bus stops reduces passengers' perceived wait time. A study conducted on bus users in Stockholm demonstrated that passengers with real-time information displays at their stop overestimated their wait-time by 9-13 percent, compared to 24-30 percent without real-time information (Kronborg et al. 2002). In London, the provision of real-time information at stops was found to reduce perceived wait time by 26 percent (Schweiger 2003). A 2007 study conducted in the Netherlands examined the introduction of passenger information display (PID) on a tram line in The Hague and found that the introduction of this service reduced perceived wait time by 20 percent (Dziekan and Kottenhoff 2007).

Wolinetz et al. (2001) conducted a survey of residents in San Francisco to identify their preferences for real-time transport information via a call center. Initially, respondents were asked to identify their preference for paying for the service; 17 percent indicated they would pay on a monthly basis, 56 percent on a call-by-call basis, and 22 percent said they would not use the service if they had to pay. A total of 53 percent were found to be willing to pay up to $\$ 1$ (USD) per call, and 38 percent indicated they would pay up to \$7 (USD) per month for this service.

The empirical evidence demonstrates that individuals are very price-sensitive when it comes to paying for real-time information. Polydoropoulou et al. (1997), in an examination of the traffic information system SmarTraveler system in Boston, found that respondents in the stated preference survey were very sensitive to an increase in price. Englisher et al. (1997) conducted a study of the same system in Boston and also found respondents to be very price-sensitive to an increase in the price of accessing traffic information. The authors found that when respondents were asked if they would pay a fee to access real-time traffic information, the projected use of the system fell by 36 percent. In 2003, a similar study of the multimodal transport information system Tavinfo in San Francisco found that respondents to a stated preference study were found to be quite sensitive to an increase in price (Khattak et al. 2003). Dedicated real-time public transit information systems also have been shown to be price sensitive. Molin et al. (2007), in a study of providing real-time information at public transit interchange points, found that the price of receiving this information was one of the most important attributes, demonstrating that respondents were highly price-sensitive. 
Wardman (2003) examined the perceived reduction in transit stop wait-time for bus passengers after the introduction of real-time information for three bus routes in London. The findings show that respondents, in a face-to-face survey, indicated that 65 percent, 24 percent, and 21 percent (at each of the routes) demonstrated that they had a shorter wait time due to the provision of real-time information. The same study examined anxiety of waiting at a bus stop at night and found that 46 percent of respondents felt safer at their bus stop if they knew when the bus was due to arrive.

In a public transit network with a large number of passengers transferring between different modes, the requirements for accurate real-time information increases. In Hong Kong, it was estimated that up to one-fifth of passengers make a transfer during their daily commute (Abdel-Aty 2001). In a study conducted in Hong Kong to examine passenger preferences for real-time information, it was found that respondents derived the greatest benefit from information delivered via a mobile device, either a mobile phone or a personal digital assistant (PDA). The authors found that as travel time and trip complexity increased, so, too, did the likelihood that an individual would choose to access real-time information using SMS (short message service) or a PDA. The results also demonstrated that females, those with higher incomes, and those on a monthly mobile phone contract were more likely to choose to obtain real-time information.

\section{Data}

\section{Data Collection}

To establish individual preferences between real-time public transit information options, a stated preference survey was conducted. The survey took place over a two-week period from the April 18 - May 9, 2005, using web-based methods. A controlled sample was taken of office workers in Dublin city center. The selected companies were contacted via their human resources departments, and the survey was then sent out centrally to all employees. A total of 1,500 surveys were distributed to the employees of the companies targeted, and 495 fully-completed surveys were returned, resulting in a response rate of 33 percent. It should be noted that this sample contains only individuals who have access to the internet and work in Dublin City center. As such, this may result in some bias in the results. 


\section{Stated Preference Design}

In the stated preference scenarios examined in this study, respondents were asked to choose between three options of accessing real-time public transit stop information: SMS, a passenger information display, or a call center. A preliminary study was conducted to ascertain individual preferences for receiving real-time public transit stop information. The results of this study are presented in Caulfield and O'Mahony (2007). The purpose of this preliminary study was to gain feed back on individual opinions of public transit information in Dublin and to inform the design of the main stated preference study (the results of which are presented in this paper). As SMS or call centers could be accessed prior to the respondent reaching the transit stop, respondents were instructed that they could choose only one of these options when they arrived at their transit stop. Each of the options considered had three cost levels, three reduction in wait-time percentages, and two options for the type of information provided. The attributes and attribute levels for each of the options considered by the respondents are as follows:

- Passenger information display: 0,10 , and 20 percent reductions in wait time at transit stop; 0,15 , and 30 c increase in public transit fare per-trip; real-time information provided or static information provided.

- SMS: 0,10 , and 20 percent reductions in wait time; 0,15 , and 30 c increase in public transit fare per trip; real-time information provided or static information provided.

- Call center: 0, 10, and 20 percent reductions in wait time; 0,15 , and 30c increase in public transit fare per trip; real-time information provided or static information provided.

An example of one of the stated choice scenarios presented to the respondents can be seen in Figure 1 .

The data collected from the stated preference survey are modelled using a nested multinomial logit model. For more detail on this approach, see Hensher et al. (2005), Train (2003), or Louviere et al. (2000). In the survey, respondents were asked to choose between different stated preference scenarios. Respondents were presented with information on each of the options provided. The call center option was described as having an automated response providing real-time information. To aid respondent comprehension of the scenarios presented, a number of pictures of real-life examples of real-time information services were shown to the respondents in the survey. The survey also was piloted to test that individuals understood the choice scenarios presented in the survey. 
Situation One: Please consider the following options A-C below, and based upon the information provided, choose your preferred method of receiving public transport information.

\begin{tabular}{|c|c|c|c|}
\hline & Option A & Option B & Option C \\
\hline & $\begin{array}{c}\text { Information display at } \\
\text { stop/station }\end{array}$ & Text message & Call centre \\
\hline $\begin{array}{l}\text { Information } \\
\text { given }\end{array}$ & $\begin{array}{c}\text { Real-time information } \\
\text { provided }\end{array}$ & $\begin{array}{c}\text { No real-time } \\
\text { information provided }\end{array}$ & $\begin{array}{c}\text { Real-time information } \\
\text { provided }\end{array}$ \\
\hline Time Saved & $\begin{array}{l}5 \% \text { decrease in wait time at } \\
\text { stop/station }\end{array}$ & $\begin{array}{l}10 \% \text { decrease in wait } \\
\text { time at stop/station }\end{array}$ & $\begin{array}{l}10 \% \text { decrease in wait } \\
\text { time at stop/station }\end{array}$ \\
\hline Cost & $\begin{array}{c}15 \mathrm{c} \text { per trip added to the price } \\
\text { of your bus or train ticket }\end{array}$ & $15 \mathrm{c}$ per message & $30 \mathrm{c}$ per call \\
\hline Please tick one & $\square$ & $\square$ & $\square$ \\
\hline
\end{tabular}

\section{Figure 1. Stated Preference Scenario}

\section{Results}

\section{Characteristics of the Sample}

Table 1 presents characteristics of the sample and compares the age and gender profiles of the sample with those of the population using 2006 Census of Ireland data (CSO 2007). The results show that the sample collected provides a fairly reasonable approximation of the population. The income levels of respondents are not compared, as this information is not released from the Central Statistics Office. The results show that 43 percent of the respondents were male and 57 percent were females. In the questionnaire, respondents were asked to indicate their age using one of the five age bands; under 24, 25-34, 35-44, 45-54 and over 55. A total of 42 percent of respondents were found to be age $25-34,24$ percent were 35-44 and 21 percent were 45-54. Table 1 presents the reported incomes of the respondents to the questionnaire. The results show a wide distribution of income. A total of 37 percent of respondents were found to earn between $€ 20,000$ and $€ 50,000$ per annum, and 41 percent earn between $€ 50,000$ and $€ 100,000$ per annum (see Table 1).

Table 2 details the characteristics of the respondents' trips to work. The findings demonstrate that approximately one-quarter of the respondents use a private car to get to work, with 22 percent driving alone and 3 percent travelling as passengers (see Table 2). The proportion of individuals that either walk or cycle to work was 14 percent and 8 percent, respectively. The remaining respondents in the sample (53\%) use public transport, with the majority of these individuals using the bus 
Table 1. Characteristics of the Sample

\begin{tabular}{|c|c|c|c|c|c|}
\hline \multirow[b]{2}{*}{ Characteristic } & & \multicolumn{2}{|c|}{ Survey Sample } & \multicolumn{2}{|c|}{2006 Census Data } \\
\hline & & $N$ & $\%$ & $N$ & $\%$ \\
\hline \multirow[t]{3}{*}{ Gender } & Male & 215 & 43 & 119,390 & 53 \\
\hline & Female & 280 & 57 & 105410 & 47 \\
\hline & Total & 495 & 100 & 224,800 & 100 \\
\hline \multirow[t]{6}{*}{ Age } & Under 24 & 35 & 7 & 33,800 & 15 \\
\hline & $25-34$ & 208 & 42 & 81,480 & 36 \\
\hline & $35-44$ & 119 & 24 & 48,746 & 22 \\
\hline & $45-54$ & 104 & 21 & 36,535 & 16 \\
\hline & Over 55 & 29 & 6 & 24,239 & 11 \\
\hline & Total & 495 & 100 & 224,800 & 100 \\
\hline \multirow[t]{13}{*}{ Income } & Less than $€ 10000$ & 9 & 2 & - & - \\
\hline & $€ 10001-€ 20000$ & 26 & 5 & - & - \\
\hline & $€ 20001-€ 30000$ & 69 & 14 & - & - \\
\hline & $€ 30001-€ 40000$ & 58 & 12 & - & - \\
\hline & $€ 40001-€ 50000$ & 53 & 11 & - & - \\
\hline & $€ 50001-€ 60000$ & 61 & 12 & - & - \\
\hline & $€ 60001-€ 80000$ & 77 & 16 & - & - \\
\hline & $€ 80001-€ 100000$ & 64 & 13 & - & - \\
\hline & $€ 100001-€ 120000$ & 37 & 8 & - & - \\
\hline & $€ 120001-€ 140000$ & 18 & 4 & - & - \\
\hline & More than $€ 140000$ & 12 & 3 & - & - \\
\hline & I do not wish to reveal my income & 11 & 2 & - & - \\
\hline & Total & 495 & 100 & - & - \\
\hline
\end{tabular}

(29\%) and the remainder using one of the light/heavy rail options. Seventeen percent of respondents said that they took more than one mode of public transit when travelling to work (see Table 2).

The reported walk times of the respondents from their home to the nearest public transit stop/station are contained in Table 2. A total of 42 percent of respondents are less than a five-minute walk and 28 percent between a 5 - and 10-minute walk from their stop/station. The reported wait times at stop/station are presented in Table 2. As with the walk time to stop/station, the majority of respondents indicated that the wait time was less than 10 minutes. A total of 32 percent indicated that they had a less than a 5-minute wait, and 44 percent were found to have a wait time of between 5 and 10 minutes. 


\section{Table 2. Trip Characteristics of the Sample}

\begin{tabular}{|c|c|c|c|}
\hline \multicolumn{2}{|l|}{ Characteristic } & \multirow{2}{*}{$\begin{array}{r}\mathbf{N} \\
70 \\
\end{array}$} & \multirow{2}{*}{$\%$} \\
\hline Mode of transport & Walk & & \\
\hline & Cycle & 39 & 8 \\
\hline & Car (Drive) & 111 & 22 \\
\hline & Car (Passenger) & 16 & 3 \\
\hline & Bus & 142 & 29 \\
\hline & Light rail & 33 & 7 \\
\hline & Rail & 83 & 17 \\
\hline & Taxi & 1 & 0 \\
\hline \multirow{2}{*}{$\begin{array}{l}\text { Transfer modes of } \\
\text { transport }\end{array}$} & Yes & 85 & 17 \\
\hline & No & 410 & 83 \\
\hline \multirow{8}{*}{$\begin{array}{l}\text { Wait time at } \\
\text { stop/station }\end{array}$} & $0-5 \mathrm{~min}$ & 83 & 32 \\
\hline & 6-10 min & 114 & 44 \\
\hline & $11-15 \mathrm{~min}$ & 39 & 15 \\
\hline & $16-20 \mathrm{~min}$ & 13 & 5 \\
\hline & $21-25 \mathrm{~min}$ & 6 & 2 \\
\hline & $26-30 \mathrm{~min}$ & - & - \\
\hline & $31-35 \mathrm{~min}$ & 2 & 1 \\
\hline & Over $35 \mathrm{~min}$ & 1 & 1 \\
\hline \multirow{8}{*}{$\begin{array}{l}\text { Walk time from } \\
\text { home to stop/station }\end{array}$} & $0.5 \mathrm{~min}$ & 108 & 42 \\
\hline & 5-10 min & 72 & 28 \\
\hline & $10-15 \mathrm{~min}$ & 33 & 13 \\
\hline & $15-20 \mathrm{~min}$ & 22 & 9 \\
\hline & $20-25 \mathrm{~min}$ & 10 & 4 \\
\hline & $25-30 \mathrm{~min}$ & 5 & 2 \\
\hline & $30-35 \mathrm{~min}$ & 1 & 0 \\
\hline & Over $35 \mathrm{~min}$ & 7 & 3 \\
\hline
\end{tabular}

\section{Opinions of Public Transit}

Table 3 presents the results of a series of questions asked to ascertain what causes respondents frustration when using public transit. The results in Table 2 are segmented by the mode of transport the respondent said they used on a daily basis, bus, rail and all respondents. Respondents were initially asked if uncertainty regarding the arrival time of their service caused frustration. A total of 80 percent of all users, 79 percent of bus users, and 78 percent of rail users indicated that uncertainty as to the arrival time of their service caused frustration. In the second question, respondents were asked if not knowing if the service had already 
departed caused them frustration. A total of 69 percent of all users, 70 percent of bus users, and 55 percent of rail users said this caused frustration. This result shows that not knowing if the public transit service had already passed caused a higher level of frustration with bus users compared to rail users. Finally, respondents were asked if uncertainty as to the departure time of their public transit service caused frustration. The results in Table 3 show that 70 percent of all users, 73 percent of bus users, and 63 percent of rail users found this uncertainty to cause frustration. This result again shows that rail users are less frustrated with uncertainty.

Table 3. Frustration with Public Transit

\begin{tabular}{|l|c|c|c|c|c|c|c|}
\hline & \multicolumn{2}{|c|}{ All Respondents } & \multicolumn{2}{c|}{ Bus Users } & \multicolumn{2}{c|}{ Rail Users } \\
\cline { 2 - 7 } & $N$ & $\%$ & $N$ & $\%$ & $N$ & $\%$ \\
\hline Uncertainty as to time of arrival \\
\hline Very frustrating & 396 & 80 & 112 & 79 & 90 & 78 \\
\hline No opinion & 54 & 11 & 11 & 8 & 12 & 10 \\
\hline Not frustrating & 45 & 9 & 18 & 13 & 14 & 12 \\
\hline Not knowing if the service has passed \\
\hline Very frustrating & 342 & 69 & 99 & 70 & 64 & 55 \\
\hline No opinion & 104 & 21 & 27 & 19 & 31 & 27 \\
\hline Not frustrating & 50 & 10 & 16 & 11 & 21 & 18 \\
\hline Uncertainty as to departure time & \multicolumn{7}{|l|}{} \\
\hline Very frustrating & 347 & 70 & 104 & 73 & 73 & 63 \\
\hline No opinion & 104 & 21 & 24 & 17 & 29 & 25 \\
\hline Not frustrating & 45 & 9 & 14 & 10 & 14 & 12 \\
\hline
\end{tabular}

Respondents to the survey were asked when they would be most likely to access real-time public transit information. As shown in Table 4, 79 percent of bus users and 78 percent of rail users said they would use real-time information if the weather was bad; 41 percent of all respondents said they would use real-time public transit information if the weather was bad; 45 percent of all respondents and 55 percent of rail respondents said they would consult real-time public transit information if using more than one mode of public transit. Of bus users, 70 percent indicated that they would access real-time public transit information if using a more than one mode of public transit. This result shows that bus users have a higher information requirement when taking more than one mode of public transit.

In the survey, respondents were asked if they would they consult real-time public transit information if they were running late. Table 4 indicates that 43 percent of all respondents, 46 percent of bus users, and 48 percent of rail users would access 
real-time information when running late. Respondents were asked if they would consult real-time public transit information if they were using a service for the first time. The results indicated that 73 percent of bus users and 63 percent of rail users would access real-time information when using a service for the first time.

Table 4. Accessing Real-Time Information

\begin{tabular}{|l|c|c|c|c|c|c|c|}
\hline & All Respondents & \multicolumn{2}{c|}{ Bus Users } & \multicolumn{2}{c|}{ Rail Users } \\
\hline & $N$ & $\%$ & $N$ & $\%$ & $N$ & $\%$ \\
\hline Bad weather & \multicolumn{7}{|c|}{} \\
\hline Would use & 203 & 41 & 112 & 79 & 90 & 78 \\
\hline No opinion & 144 & 29 & 11 & 8 & 12 & 10 \\
\hline Would not use & 149 & 30 & 18 & 13 & 14 & 12 \\
\hline When using more than one mode \\
\hline Would use & 223 & 45 & 99 & 70 & 64 & 55 \\
\hline No opinion & 149 & 30 & 27 & 19 & 31 & 27 \\
\hline Would not use & 124 & 25 & 16 & 11 & 21 & 18 \\
\hline When running late & \multicolumn{7}{|l|}{} \\
\hline Would use & 213 & 43 & 65 & 46 & 56 & 48 \\
\hline No opinion & 109 & 22 & 50 & 35 & 42 & 36 \\
\hline Would not use & 173 & 35 & 27 & 19 & 19 & 16 \\
\hline If using a service for the first time & 342 & 69 & 104 & 73 & 73 & 63 \\
\hline Would use & 109 & 22 & 24 & 17 & 29 & 25 \\
\hline No opinion & 45 & 9 & 14 & 10 & 14 & 12 \\
\hline Would not use & 45
\end{tabular}

\section{Opinion of Real-Time Public Transit Information Provision}

In the survey, respondents were asked to rate a number of aspects of public transit information provision in Dublin using a five-point scale from "very good" (5) to "very poor" (1). For each of the public transit information options analysed, an average rating was taken for bus users, rail users, and "other" users (drivers, walkers, and cyclists). Respondents were asked to rate the quality of maps provided at bus stops/train stations. Bus users were found to have the lowest rating of 1.88, followed by the "other" user group and rail users with ratings of 2.02 and 3.92, respectively (see Table 5). These results suggest that bus users have the lowest opinion of maps provided at bus stops, followed by the "other" user group and rail users. When asked to evaluate the provision of timetables, bus users were found to have the lowest rating of 2.05, followed by the "other" group with a rating of 2.10. Rail users were shown to have a considerably higher rating of 4.05 , indicating that the majority of rail users in the sample were satisfied with the quality of timetables provided at rail stations. 
Rail users were found to have the highest average rating of 3.99 when evaluating the quality of public transit websites. The "other" user group were found to have the lowest rating of 2.14, followed by bus users with a rating of 2.17 (see Table 5). The average rating for the bus and the "other" user groups were very similar, indicating these user groups found the quality of public transit websites to be equally poor. One explanation for this may be that the main internet site for urban rail services in Dublin provides passengers with real-time arrival information. The results show that each of the different user groups was found to equally rate the availability of information on the cost public transit, regardless of mode, with a low ranking.

Table 5. Opinion of Public Transit Information Services

\begin{tabular}{|l|c|c|c|}
\hline Option & Bus Users & Rail Users & Others \\
\hline $\begin{array}{l}\text { Maps provided at bus stops/ } \\
\text { train stations }\end{array}$ & 1.88 & 3.92 & 2.02 \\
\hline $\begin{array}{l}\text { Timetables provided at bus } \\
\text { stops/train stations }\end{array}$ & 2.05 & 4.05 & 2.10 \\
\hline Public transit websites & 2.17 & 3.99 & 2.14 \\
\hline $\begin{array}{l}\text { Availability of information on } \\
\text { the cost of your trip }\end{array}$ & 1.99 & 2.09 & 1.98 \\
\hline
\end{tabular}

\section{Modelling Results}

The nested multinomial logit model results estimated in this study are presented in Table 6. For mode detail on this modelling approach, see Hensher et al. (2005). The nested structure that provided the most consistent results in terms of $\rho^{2}(0)$ and $\rho^{2}(\mathrm{c})$ values is presented in Figure 2. As shown in Figure 2, the nested structure had two limbs, SMS information on one limb, and passenger information display and call center on the other. The model specifications for all three models produce good $\rho^{2}(0)$ and $\rho^{2}(\mathrm{c})$ values. The model $1 \rho^{2}(0)$ and $\rho^{2}(\mathrm{c})$ values were estimated to be 0.265 and 0.222 ; the values for model 2 (bus user) were 0.281 and 0.231 , and 0.271 and 0.211 for model 2 (rail user). 
Table 6. Nested Multinomial Logit Models

\begin{tabular}{|l|l|c|c|c|}
\hline \multicolumn{2}{|c|}{ Variables } & Model 1 & $\begin{array}{c}\text { Model 2 } \\
\text { (Bus Users) }\end{array}$ & $\begin{array}{c}\text { Model 3 } \\
(\text { Rail Users) }\end{array}$ \\
\hline \multirow{4}{*}{ SMS } & Wait time saved & $-0.032(-4.3)^{* *}$ & $-0.034(-5.6)^{* *}$ & $-0.027(-3.6)^{* *}$ \\
\cline { 2 - 5 } & Cost & $-0.054(-6.1)^{* *}$ & $-0.042(-4.8)^{* *}$ & $-0.073(-2.7)^{* *}$ \\
\cline { 2 - 5 } & Information & $-0.879(-7.3)^{* *}$ & $-1.062(-2.0)^{*}$ & $-0.718(-6.7)^{* *}$ \\
\hline \multirow{4}{*}{ Call Center } & Wait time saved & $-0.017(-2.6)^{* *}$ & $-0.031(-2.1)^{*}$ & $-0.023(-4.4)^{* *}$ \\
\cline { 2 - 5 } & Cost & $-0.068(-7.6)^{* *}$ & $-0.031(-7.3)^{* *}$ & $-0.065(-2.7)^{* *}$ \\
\cline { 2 - 5 } & Information & $-1.110(-7.2)^{* *}$ & $-1.172(-7.6)^{* *}$ & $-0.848(-3.7)^{* *}$ \\
\hline \multirow{2}{*}{$\begin{array}{l}\text { Passenger } \\
\text { information }\end{array}$} & Wait time saved & $-0.043(-7.1)^{* *}$ & $-0.088(-2.3)^{*}$ & $-0.042(-4.1)^{* *}$ \\
\cline { 2 - 6 } & Cost & $-0.054(-9.6)^{* *}$ & $-0.038(-9.4)^{* *}$ & $-0.039(-4.2)^{* *}$ \\
\cline { 2 - 6 } & Information & $-0.947(-7.8)^{* *}$ & $-1.215(-9.5)^{* *}$ & $-1.037(-2.8)^{* *}$ \\
\hline WAIT & $0.112(4.1)^{* *}$ & $0.696(9.1)^{* *}$ & $0.309(2.9)^{* *}$ \\
\hline FRUST & $0.048(2.6)^{* *}$ & $0.088(2.0)^{*}$ & $0.035(2.4)^{*}$ \\
\hline DEPT & $0.116(2.8)^{* *}$ & $0.218(2.1)^{*}$ & $0.108(3.3)^{* * *}$ \\
\hline FIXW & $-0.175(-4.0)^{* *}$ & $-0.502(-2.8)^{* * *}$ & $-0.572(-4.2)^{* *}$ \\
\hline MULTI & $0.139(2.0)^{*}$ & $0.241(2.9)^{* *}$ & $0.147(3.1)^{* * *}$ \\
\hline WALKSTOP & $0.417(1.9)^{*}$ & $0.324(4.5)^{* * *}$ & $0.781(2.9)^{* *}$ \\
\hline N & 1980 & 542 & 440 \\
\hline$\rho^{2}(0)$ & 0.265 & 0.281 & 0.271 \\
\hline$\rho^{2}(c)$ & 0.222 & 0.231 & 0.211 \\
\hline
\end{tabular}

* Significant at the $95 \%$ confidence level

** Significant at the $99 \%$ confidence level

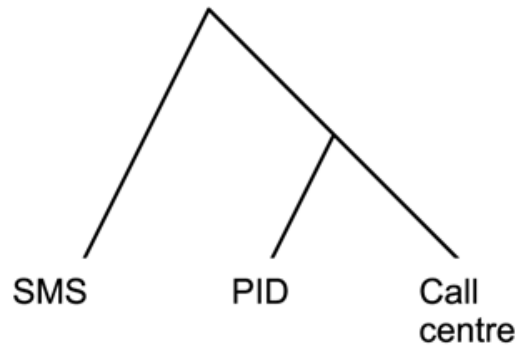

Figure 2. Nested Model Structure

The estimated coefficients for wait time saved for the SMS option were found to be negative and significant at the $99 \%$ confidence level (see Table 6). The reduction in wait time coefficient for bus users was found to be -0.034 , and -0.027 and 
for the rail model (see Table 6). These estimates demonstrate that bus users derive a slightly higher utility from wait time saved compared to rail users.

The coefficients for cost of SMS information were found to be negative and significant at the 99\% confidence level (see Table 6). Bus users were shown to have the lower cost disutility $(-0.042)$ compared to rail users $(-0.073)$. The estimated cost coefficients indicate that bus users are the least likely to object to paying for information via SMS. The information coefficient for SMS information was estimated to be highest for bus users $(-1.062)$, followed by rail users $(-0.718)$ (see Table 6). These findings suggest that, as with the other real-time information options, bus users derive the highest benefit from real-time information provided via SMS.

The coefficients for wait-time saved using a call center were found to be negative and significant at either the $95 \%$ or $99 \%$ confidence intervals (see Table 6). Bus users were estimated to derive the highest utility from wait-time saved with an estimated coefficient of -0.031 . These findings indicate that bus users derive the highest benefit from a reduction in wait-time while at their bus stop. The higher preference for a reduction in wait time by bus users compared to rail users may be attributed to the perceived lack of reliability in arrival of bus services relative to rail services.

The cost coefficients for information provision via a call center were shown to be negative and significant at the $99 \%$ confidence level in each of the segmented models. Bus users were found to have the lowest cost coefficient $(-0.031)$, followed by rail users $(-0.065)$ (see Table 6$)$. These cost coefficients indicate that bus users are less likely to object to paying to use the call center option compared to rail users.

The wait time saved coefficient estimates for passenger information display were estimated to be negative and significant at the $95 \%$ or $99 \%$ confidence levels (see Table 6$)$. The bus user model produced the highest negative coefficient $(-0.088)$, followed by rail users $(-0.042)$. This result demonstrates that bus users derive the highest utility from the provision of information via a passenger information display while at a stop/station. These findings show that time saving is more important to bus users compared to rail users.

The cost coefficients for information provision via passenger information display were found to be negative and significant at the $99 \%$ confidence level (see Table 6). The disutility of cost was found to be lowest for bus users, with an estimated coefficient of -0.38 , followed by rail users $(-0.039)$. The coefficients for bus and rail 
users were estimated to be very similar. This demonstrates that both groups have a similar willingness to pay for real-time information from a passenger information display. This finding demonstrates that public transit users are more open to paying for the provision of transit stop/station information provided via a passenger information display, compared to the other user groups.

The information coefficients for the provision of information via a passenger information display were found to be negative and significant at the $99 \%$ confidence level for all models (see Table 6). A negative value implies a preference for real-time information rather than static information. Of the estimated coefficients, bus users were found to have the highest value (-1.215), followed by rail users (-1.037). These findings demonstrate that bus users derive a higher benefit from the provision of real-time information being provided via a passenger information display compared to the other user groups.

A comparison between the methods of receiving public transit information demonstrates that all three user groups derive the highest utility for wait-time saved when the information was provided via a passenger information display.

\section{Additional Variables}

This section of the paper examines a number of additional variables that were added to ascertain how certain factors impact the utility derived from real-time public transit stop information. The first variable examined in this section measures how wait time impacts the utility derived from real-time public transit stop information. The wait-time variable is a categorical variable and is defined in Table 7. A positive value for WAIT would indicate that as wait time increases, individuals are likely to derive a benefit from the use of real-time public transit information. The WAIT coefficients were estimated to be significant at the $99 \%$ confidence level (see Table 6). Each of the coefficients estimated was found to be positive. This indicates that as the wait time at stop/station increases, so, too, does the utility derived from accessing real-time public transit information. This result is in line with other studies that have shown the provision of real-time public transit stop information reduces perceived wait times and improves user perceptions of public transit (Schweiger 2003, Dziekan and Kottenhoff 2007). A comparison between the wait-time coefficients demonstrates that wait time was most likely to impact upon bus users (0.696), as this coefficient was found be higher than the coefficient estimated for rail users (0.309) (see Table 6). 


\section{Table 7. Description of Additional Variables}

\begin{tabular}{|l|l|}
\hline Variable & Description \\
\hline DEPT & $\begin{array}{l}\text { Categorical variable - Respondent departure time where the values 1-8 } \\
\text { represent the following: before 6:30am, 6:30-7:00am, 7:00-7:30am, } \\
7: 30-8: 00 \mathrm{am}, 8: 00-8: 30 \mathrm{am}, 8: 30-9: 00,9: 00-9: 30 \text { and after 9:30 }\end{array}$ \\
\hline CONMOB & Dummy variable - If pay monthly contract equals 1, if pay-as-you-go equals 0 \\
\hline FRUST & Categorical variable - Sums the individual reported values presented in Table 2 \\
\hline FIXW & $\begin{array}{l}\text { Dummy variable - If respondent has fixed set working hours equal to 1, } \\
\text { 0 otherwise }\end{array}$ \\
\hline MULTI & $\begin{array}{l}\text { Dummy variable - Those that take more than one mode of public transit on } \\
\text { their journey to work take a value of 1, otherwise 0 }\end{array}$ \\
\hline WAIT & $\begin{array}{l}\text { Categorical variable - Where values 1-7 represent the following: } \\
0-5 \text { minutes, 5-10 minutes, 10-15 minutes, 15-20 minutes, 20-25 minutes, } \\
25-30 \text { minutes and more than 30 minutes }\end{array}$ \\
\hline WALKSTOP & $\begin{array}{l}\text { Categorical variable - Where values 1-7 represent the following: } \\
0-5 \text { minutes, 5-10 minutes, 10-15 minutes, 15-20 minutes, 20-25 minutes, } \\
25-30 \text { minutes and more than 30 minutes }\end{array}$ \\
\hline
\end{tabular}

The first "work pattern" variable to be examined was daily departure time. The purpose of examining this variable is to ascertain if departure time impacts an individual's choice between transit information options. A categorical variable for departure time DEPT was created and is defined in Table 7. A negative or low coefficient value would indicate those who depart early derive a higher utility from transport information than those who depart later. The results for departure time were found to be significant at the $99 \%$ confidence level (see Table 6). The departure time coefficients were found to be positive, indicating that as departure time increases, so, too, does the likelihood that the individual will derive a benefit from real-time information. The bus user departure time coefficient was found to be greater than that of the rail user coefficient. This result suggests that bus users, who depart later to work, are more likely to derive a benefit from real-time information, compared to the same group of rail users.

The dummy variable FIXW was created to represent those individuals who have to arrive at work at a specific time each day. This variable examines if those on fixed start or flexible start times are more likely to use real-time information. The dummy variable FIXW is defined in Table 6. A positive value for the FIXW variable would indicate that those individuals who have to arrive at work at a specific time are more likely to use real-time information and vice versa. The FIXW variables also were found to be negative and significant at the $99 \%$ confidence level (see Table 6). 
This model demonstrates that individuals who do not have a fixed working schedule are more likely to derive a benefit from real-time public transit information.

The results from Table 4 are used to create a variable to measure frustration while waiting at a public transit stop/station. The FRUST variable adds the individual responses to the questions posed in Table 3 to produce a combined frustration score (see Table 7). If the respondent indicates, for example, that not knowing the arrival time was frustrating; it is indicated by $a+1$, which is then added to their responses to the other two questions. This method was used to calculate the total frustration score. Therefore, the final frustration score of the individual is the sum of the responses to each of the individual questions. A positive FRUST score would indicate that the respondent was frustrated while waiting for his/her public transit service to arrive. The FRUST coefficient in each of the models examined was found to be positive and significant at either the $95 \%$ or $99 \%$ confidence levels (see Table 6). This finding indicates that as the frustration score increases, so, too, does the likelihood that the individual will derive a benefit from real-time public transit information. This result was as one would expect. The FRUST variable was estimated to be 0.088 for bus users and 0.035 for rail users (see Table 6). This result indicates that bus users who experience high frustration levels are more likely to derive a benefit from real-time public transit information compared to rail users experiencing the same levels of frustration.

Individuals who transfer between modes of transport to complete a single journey require information on two or more modes of transport. The MULTI variable was a dummy variable that takes a value of 1 if the respondent indicated that he/she uses more than one mode of transport to travel to work, and 0 otherwise (the MULTI variable is defined in Table 7). In model 1, the MULTI variable was found to be positive and significant at the $95 \%$ confidence level with a $t$-ratio of 2.0 (see model 1 , Table 6 ). This positive value suggests that, all things being equal, those who undertake a trip using more than one public transit service are more likely derive a benefit from real-time public transit information. The MULTI variable was also found to be significant in the bus and rail models. The bus model coefficient was estimated to be 0.241 , and the rail model coefficient was found to be 0.147 (see models 2 and 3 in Table 6). A comparison between the three results for the MULTI variable shows that bus users that transfer between modes of public transit derive the greatest benefit from the provision of real-time public transit information. 
The WALKSTOP variable examines the impact the distance a respondent has to walk to his/her nearest bus stop or train station has upon the benefits derived from real-time public transit information. The WALKSTOP variable is a categorical variable (defined in Table 7). The WALKSTOP variable in model 1 was found to have a positive coefficient value of 0.417 and significant at the $99 \%$ level ( $t$-ratio of 3.2) (see model 1 in Table 6). This result indicates that as the time taken to walk to the stop increases, so, too, does the likelihood that the respondent will derive a benefit from real-time public transit information. The bus user and rail user WALKSTOP coefficients were estimated to be 0.324 and 0.781 , respectively (see models 2 and 3 in Table 6). This finding shows rail users with longer walk times derive a greater benefit from real-time public transit information compared to bus users. This result differs from the other results presented in this paper in that rail users were found in this instance to derive a greater benefit from real-time public transit information. One possible explanation for this result is that on average rail users had longer walk times to reach their station compared to bus users.

\section{Conclusions}

The research presented in this paper examines an individual's choice between realtime information options and investigates how this choice varies between bus and rail users. This paper also addresses how a number of factors such as work schedule and frustration experienced while waiting at a bus stop/train station can impact the utility derived from real-time public transit information. While the results presented in this paper provide an indication of the individual preferences for real-time public transit stop information, it should be noted that the sample used in this study was that of office-based workers in Dublin's central business district, and as such may not be representative of the whole population.

The need for real-time public transit stop information is clearly outlined in the results. The vast majority of respondents $(80 \%)$ indicated that not knowing the arrival time of their service caused frustration. A similar result was found when respondents were asked if not knowing had their bus/rail service passed caused frustration; 69 percent found this frustrating. The findings presented in this paper show that for each of the different methods of obtaining real-time information considered, bus users were found to derive the greatest benefit from these services. This finding was echoed in the additional variables examined in this paper, such as in the frustration and wait-time variables. These results show that bus 
users who experience longer wait times and greater frustration levels were more likely to derive a benefit from using real-time information.

When examining the preferences for the different methods of accessing real-time public transit information, the results show respondents derive the greatest benefit from real-time public transit stop information displays. This result was as one would expect, as this is one of the most effective methods of relaying real-time public transit stop information. Accessing information via SMS was found to be the second most attractive option to respondents, as respondents derived a greater utility from this option compared to using a call center.

The results from this paper demonstrate which public transit users are most likely to benefit from the provision of real-time information. The findings presented in this paper can be used to demonstrate how to prioritize investment in real-time information by highlighting the users who are most likely to benefit from realtime information services. To this extent, the results of this research demonstrate that bus users derive the greatest benefit from the provision of real-time public transit information, and as such, investment should be concentrated on providing bus users with real-time public transit information. The results also demonstrate that individuals derive a benefit from the provision of real-time information and are willing to pay for this information. The research presented in this paper could be further extended by examining different types of trips such as off-peak trips, leisure trips, and retail trips. As previously mentioned, this study is limited in that it concentrates on office-based workers in Dublin City center. A further extension to this study would be to look at other groups of respondents such as individuals who work in the suburbs and in industrial areas.

\section{Acknowledgment}

The research was supported by the Department of Transport under the Pilot Transport Research Programme, administered by the Higher Education Authority.

\section{References}

Caulfield, B., and M. M. O'Mahony. 2007. An examination of the public transit information requirements of users. IEEE Transactions on Intelligent Transport Systems 8(1). 
CSO. 2007. Census of population of Ireland 2006, Place of Work, Census of Anonymised Records (POWCAR) Users Guide. CSO, Dublin, Ireland.

Dublin Bus. 2007. Available at http://www.dublinbus.ie/home/bus_text.asp [accessed 20th June 2007].

Dziekan, K., and K. Kottenhoff. 2007. Dynamic at-stop real-time information displays for public transport: effects on customers. Transportation Research Part A: Policy and Practice 41(6): 489-501.

Englisher, L., R. Juster., S. Bergman., and A. Willson. 1997. Promoting advanced traveller information systems among cellular and land-line phone users. Transportation Research Record 1588: 63-69.

Hensher, D. A., J. M. Rose, and W. H. Greene. 2005. Applied choice analysis: A primer. London: Cambridge University Press.

Irish Rail. 2007. Available at http://www.iarnrodeireann.ie/news_centre/general_ news.asp?action=view\&news_id=71 [accessed 19th June 2007].

Kronborg, P., A. Lindkvist, and E. Schelin. 2002. Fungera transportinformatik I prakitken? 4 fallstudier I syfte att undvika misstaf I framtiden (No. 2002:18) TFK Stockhlom.

Khattak. A. J., Y. Yim., and L. S. Prokopy. 2003. Willingness to pay for travel information. Transport Research Part C 11:137-159.

Louviere, J. J., D. A. Hensher, and J.D. Swait. 2000. Stated choice methods: Analysis and application. London: Cambridge University Press.

Molin, E., C. Chorus, and R. van Sloten. 2007. The need for advanced public transit information services when making transfers. 86th Annual Meeting of the Transportation Research Board (CD-ROM), Washington, D.C.

Nijkamp, P., G. Pepping, and D. Banister. 1996. Telematics and transport behaviour, Chapter 7: Public transit information systems: An English case study. Heidelburg: Springer.

Polydoropoulou, A., D. Gopinath, and M. Ben-Akiva. 1997. Willingness to pay for advanced traveller information systems: SmarTraveler case study. Transportation Research Record 1588: 1-9.

Schweiger, C. L. 2003. Customer and media reactions to real-time bus arrival information systems. Transportation Research Board, Report No. 48. 
Tam, M. L, and W. H. Lam. 2005. Modelling the market penetration of personal public transit information systems in Hong Kong. Journal of Intelligent Transportation Systems 9(2): 81-89.

Train, K. 2003. Discrete choice methods with simulation. London: Cambridge University Press.

Warman, P. 2003. Measured impacts of real-time control and information systems for bus services. Transport Direct, UK Department for Transport.

Wolinetz, L., A. J. Khattak, and Y. B. Yim. 2001. Why will some individuals pay for travel information when it can be free? Analysis of a Bay Area traveller survey. Transport Research Record 1759: 9-18.

\section{About the Authors}

BRIAN CAUlfield (brian.caulfield@tcd.ie) is a lecturer in Civil Engineering in the Department of Civil, Structural, and Environmental Engineering at Trinity College Dublin. He has published and has interests in public transit services, stated preference modelling, environmental impacts of transport, and road safety.

MARGARET O'MAHONY (margaret.omahony@tcd.ie) is the Professor of Civil Engineering and Director of the Centre for Transport Research at Trinity College Dublin. She leads a large number of interdisciplinary research projects that focus on transport policy, transport planning, network modelling, optimisation of transport networks, demand management, transport pricing, urban freight solutions, vehicle instrumentation, and innovative road materials. 